\title{
Trayectorias sociales y legitimidades político-religiosas en el Senado argentino a comienzos del siglo $\mathrm{XXI}^{*}$
}

\begin{abstract}
Resumen
El presente artículo indaga en la dimensión religiosa de las trayectorias sociales y los discursos parlamentarios de dos senadoras argentinas que participaron como tales en el debate sobre la ley de matrimonio igualitario en 2010. Lo hace desde una perspectiva sociológica cualitativa, valiéndose de una pluralidad de fuentes, tales como entrevistas en profundidad, currículums en línea, bases de datos y artículos de prensa, entre otras. El trabajo muestra cómo los significados religiosos forman parte de los universos de sentido en los que estas políticas fueron socializadas y a los que recurren para interpretar la realidad y fundamentar sus posiciones y, al mismo tiempo, la manera en que lo religioso funciona como criterio legitimador de su acción política. De esta forma, aporta al conocimiento de los múltiples y complejos vínculos entre religión y política en las elites políticas de la Argentina actual.
\end{abstract}

\section{Palabras clave}

Tesauro: élite, socialización, catolicismo, parlamento, discurso.

Autor: matrimonio igualitario.

Referencia para citar este artículo: Levita, Gabriel. "Trayectorias sociales y legitimidades políticasreligiosas en el Senado argentino a comienzos del siglo XXI". Anuario de Historia Regional y de las Fronteras 23.2 (2018): 199-219.

Gabriel Levita: doctor en Ciencias Sociales de la Universidad de Buenos Aires, Argentina y Doctor en Estudios Políticos de la École des Hautes Études en Sciences Sociales (doctorado en cotutela UBAEHESS) (2014). Licenciado en Sociología (Diploma de Honor), Universidad de Buenos Aires, Argentina (2009). Profesor adjunto regular de "Sociología de las Organizaciones", Departamento de Planificación y Políticas Públicas, Universidad Nacional de Lanús (UNLa), Lanús, Buenos Aires, Argentina. Ayudante docente de primer interino de "Historia del Conocimiento Sociológico II", Carrera de Sociología, Facultad de Ciencias Sociales, Universidad de Buenos Aires (UBA), Buenos Aires, Argentina. Código ORCID: https://orcid.org/0000-0003-4378-2076. Correo electrónico: glevita@unla.edu.ar y levgab@hotmail.com.

\footnotetext{
* El artículo se deriva de la investigación doctoral del autor "Elites políticas y nación: trayectorias sociales y representaciones sobre lo nacional de los senadores (2001-2011)" (tesis en cotutela entre la Universidad de Buenos Aires y la École des Hautes Études en Sciences Sociales, defendida en 2014). La misma fue financiada por el Consejo Nacional de Investigaciones Científicas y Técnicas de la Argentina (CONICET).
} 


\title{
Social Trajectories and Political-Religious Legitimacies in the Argentine Senate of early 21st Century
}

\begin{abstract}
In this article we analyze the religious dimension of the social trajectories and the parliamentary speeches of two Argentine senators who participated in the session where the bill for same sex marriage was passed in 2010. It is done from a qualitative sociological perspective using different sources, such as in-depth interviews, on-line résumés, databases and press articles, among others. The study shows how religious meanings are part of the universe these politicians use to interpret reality and justify their political standings. And, at the same time, religion works as a criterion to legitimize political actions. Thus, it contributes to the knowledge of the multiple and complex links between religion and politics in current Argentine political elites.
\end{abstract}

Keywords

Thesaurus: Elite, Socialization, Catholicism, Parliament, Speeches. Author's keywords: Same Sex Marriage.

\section{Trajetórias sociais e legitimações político religiosas no Senado argentino no início do século XXI}

\section{Resumo}

Este artigo explora a dimensão religiosa das trajetórias sociais e dos discursos parlamentares de duas senadoras argentinas que participaram como tal no debate sobre a lei do casamento igualitário em 2010. A exploração é feita desde uma perspectiva sociológica qualitativa, usando uma pluralidade de fontes, como entrevistas em profundidade, currículos online, bases de dados e artigos de imprensa, entre outros. O trabalho mostra como os significados religiosos são parte dos universos de significado em que essas politicas foram socializadas e aqueles que recorrem a interpretar a realidade e fundamentam suas posições e, ao mesmo tempo, a maneira como o religioso funciona como critério de legitimação de sua ação política. Desta forma, contribui para o conhecimento dos múltiplos e complexos vínculos entre religião e política nas elites políticas da atual Argentina.

\section{Palavras chave}

Thesaurus: elites, socialização, catolicismo, parlamento, discurso.

Palavras-chave do autor: casamento igualitário. 


\section{Introducción}

Si la idea de que la religión y la política constituyen esferas separadas y autónomas entre sí concita dudas razonables en buena parte del mundo académico, los estudios sobre la cuestión en América Latina dejan muy poco lugar para imaginar a estos dos ámbitos de acción como separados y diferenciados. Tanto en trabajos orientados a problemas contemporáneos como a procesos socio-históricos, la mutua imbricación entre lo religioso y lo político ha dado lugar a abundantes reflexiones en torno a las formas que esta relación adquiere. A su vez, poner el foco en las trayectorias y discursos de las elites políticas permite plantear la pregunta acerca de las características de los grupos dirigentes y ver en qué medida los solapamientos político-religiosos no se dan únicamente en el nivel de los militantes o de las bases, sino en las propias categorías dirigentes.

En la Argentina en particular, lo político en lo religioso, lo religioso en lo político e incluso las dinámicas político-religiosas poseen larga data y constituyen un factor explicativo de la historia política del país a lo largo del siglo XX, ${ }^{1}$ no obstante los estudios sobre el peso de lo religioso en las elites políticas de la actualidad son más bien escasos. ${ }^{2}$ Por ello nos preguntamos ¿qué tipo de solapamientos se dan entre religión y política en las elites políticas argentinas? ¿Cómo interviene lo religioso en sus trayectorias sociales y en las ideas que esgrimen en los debates parlamentarios? Reconstruimos las trayectorias sociales de dos políticas argentinas que ocuparon sendas bancas en el Senado nacional al momento del debate y la sanción de la ley de matrimonio igualitario en 2010 y las analizamos en relación con sus intervenciones en dicha sesión. Trabajamos sobre los modos en que las socializaciones, sociabilidades e ideas religiosas y políticas se vinculan entre sí.

Se trata de María Rosa Díaz y Liliana Teresita Negre de Alonso, cuyas trayectorias poseen una serie de similitudes y diferencias que nos permite comparar distintas articulaciones entre sus recorridos de vida y sus actuaciones en ocasión de un debate en el que se pusieron en juego significados religiosos, tanto por parte de los legisladores dentro del recinto como de los diferentes movimientos sociales -religiosos o noque tomaron la palabra públicamente. Ambas senadoras fundamentaron su decisión basadas en argumentos religiosos, pero votaron de manera contraria un proyecto de ley de gran relevancia que dominó el debate público del momento.

Desde el punto de vista analítico, diferenciamos a la Iglesia Católica del Catolicismo. La primera constituye una institución jerárquica afianzada en las distintas realidades nacionales de cada país con su propia historia, sus normativas y su doctrina. Posee

\footnotetext{
1 Humberto Cucchetti y otros, "Caminos sinuosos: nacionalismo y catolicismo en la Argentina contemporánea", El altar y el trono. Ensayos sobre el catolicismo político latinoamericano, eds. A. Rivero y F. Colom González (Barcelona: Antrophos/Unibiblos, 2006) 155-190.

${ }^{2}$ Juan Cruz Esquivel, "Religious and Politics in Argentina. Religious influence on parliamentary decisions on sexual and reproductive rights", Latin American Perspectives 43 (2016):133-143; Gabriel Levita, "Política y religión en el Senado argentino: el debate sobre el matrimonio para personas del mismo sexo en 2010", Revista Latinoamericana de Investigación Crítica, CLACSO, 3.5 (2016): 39-58.
} 
el monopolio de la administración de los bienes de salvación y controla quiénes están dentro y quiénes fuera del espacio institucional. ${ }^{3}$ Por su parte, el catolicismo remite a un espacio plural y heterogéneo constituido por un entramado de ámbitos de socialización y sociabilidad, que provee un referente identitario flexible y alberga en su interior diversos grupos con distintos intereses y tipos e intensidades de prácticas y creencias. Por eso mismo, corresponde hablar de catolicismos en plural. ${ }^{4}$

El trabajo apunta a mostrar cómo los significados religiosos ligados al catolicismo forman parte de los universos de sentido en los que estas políticas fueron socializadas $\mathrm{y}$ a los que recurren para interpretar la realidad y fundamentar sus posiciones $\mathrm{y}$, al mismo tiempo, la manera en que funcionan como criterio legitimador de su acción política. Esto se da tanto en quien milita en organizaciones católicas como en quien no lo hace. El trabajo también discute con el sentido común de que lo religioso in toto se opone al reconocimiento de derechos a las minorías sexuales.

El artículo se encuentra organizado en tres apartados y unas conclusiones. En la primera sección, construimos un recorrido socio histórico por las relaciones entre catolicismo y política en la Argentina del siglo XX que permite comprender el peso del factor religiosos en las socializaciones y sociabilidades de las elites políticas argentinas. En la segunda parte, reconstruimos las trayectorias sociales de las dos senadoras en cuestión. El tercer apartado analiza y compara las intervenciones parlamentarias de estas dos políticas durante el debate por el matrimonio igualitario en el Senado en el año 2010. Finalmente, las conclusiones buscan comprender la articulación entre trayectorias e ideas a partir de los procesos de secularización entendidos no como una separación de lo religioso y lo político, sino como una reconfiguración de dicho vínculo.

\section{Del conflicto triangular a la laicidad subsidiaria: catolicismo y política en la historia argentina}

El peso del factor religioso en las socializaciones y sociabilidades de las elites argentinas se enmarca en los complejos vínculos entre religión y política que tuvieron lugar en el país desde su misma organización como Estado-nación. Cucchetti, Donatello y Mallimaci plantean la existencia de un conflicto triangular entre liberalismo, socialismo y catolicismo que posee un carácter explicativo central en el devenir de las instituciones estatales, la política, la cultura, las identidades y las ideas de nación en la Argentina del siglo XX. ${ }^{5}$ En ese esquema tripartito, lo religioso representaría un vestigio del pasado colonial, símbolo del atraso y la repudiable

\footnotetext{
${ }^{3}$ Pierre Bourdieu, "Une interprétation de la théorie de la religion selon Max Weber", Archives européennes de sociologie, 12 (1971): 3-21.

${ }^{4}$ Verónica Giménez Béliveau e Gabriela Irrazábal, "Católicos en Argentina: hacia una interpretación de su diversidad", Sociedad y religión 20.32-33 (2010): 42-59.

5 Humberto Cucchetti y otros, "Caminos sinuosos: nacionalismo y catolicismo en la Argentina contemporánea"; Fortunato Mallimaci, "El catolicismo argentino desde el liberalismo integral a la hegemonía militar", 500 años de cristianismo en Argentina, AA. VV. (Buenos Aires: CEHILA, 1997): 197-365.
} 
herencia hispánica, que estaría condenado a desaparecer y, mientras tanto, a ser relegado al espacio de lo privado.

Sin embargo, en la práctica, esos enfrentamientos eran más complejos y estaban tamizados por múltiples solapamientos entre lo religioso y lo político, atravesados a su vez por relaciones de cooperación y tensión entre diversos actores. "Anticlericalismo" no significaba necesariamente "anticatolicismo" y las iniciativas para una mayor separación institucional entre la Iglesia Católica y el Estado nacional podían provenir de actores fuertemente identificados con el catolicismo. ${ }^{6}$ En ese contexto, encontramos la expulsión del nuncio apostólico y las leyes de registro civil y de educación laica, pública y gratuita sancionadas en 1884 y la de matrimonio civil de 1888 como algunos de los principales hitos de una relación para la época desigual y problemática entre la Iglesia y el Estado.

Ahora bien, hacia finales del siglo, el recrudecimiento de las protestas sociales, a la par del surgimiento y crecimiento del movimiento obrero y la llamada cuestión social, impactó fuertemente en las elites políticas e intelectuales de la época, conduciendo a una relación más armónica entre los sectores antes en pugna. Desde el mundo católico provendría, en ese sentido, una serie de respuestas enmarcadas en una doble estrategia de catolizar "por arriba" a las elites dirigentes y de catolizar "por abajo" a las clases populares ocupándose de la cuestión social y ganándole terreno al socialismo y al anarquismo. Estos esfuerzos coherentes y sostenidos en el tiempo estuvieron orientados a penetrar en el aparato estatal y conquistar con cuadros del movimiento católico posiciones de poder e influencia en la sociedad y sus instituciones con miras a instaurar a la Iglesia Católica en el centro de la vida nacional. La lucha por la construcción de memorias y las apuestas por identificar el nacimiento de la patria con el catolicismo cobraron un fuerte impulso.

Desde esta perspectiva se señala que a partir de la década de 1930 el tipo de catolicismo dominante en la Argentina es de carácter integral. Retomando a Émile Poulat, Mallimaci afirma que se trata de un catolicismo romano, intransigente e inquebrantablemente anti-liberal. ${ }^{7}$ Rechaza quedar relegado al terreno de las prácticas culturales o privadas y se propone penetrar todos los ámbitos de la vida pública para construir una sociedad cristiana con una fuerte dimensión popular. Este catolicismo actuaba como un nacionalismo de sustitución que homologaba la identidad nacional a la identidad católica tal como la entendían los integrales. La nación habría nacido, entonces, forjada por la Iglesia y el Ejército al calor de las luchas contra la dominación militar e intelectual extranjera.

\footnotetext{
${ }^{6}$ Roberto Di Stefano, "La excepción argentina. Construcción del Estado y de la Iglesia en el siglo XIX", Procesos: revista ecuatoriana de historia 40 (2014): 91-114; Ignacio Martínez, Una nación para la Iglesia argentina. Construcción del Estado y jurisdicciones eclesiásticas en el siglo XIX (Buenos Aires: Academia Nacional de la Historia, 2013).

${ }^{7}$ Fortunato Mallimaci, "Catolicismo y militarismo en la Argentina (1930-1983). De la Argentina liberal a la Argentina católica”, Revista de Ciencias Sociales 4 (1996): 192.
} 
El modelo de Estado y de nación que enarbolaba el catolicismo integral se consolidó en el plano de las identidades y las representaciones, pero también a nivel institucional a partir de su penetración en distintas instituciones estatales, como las Fuerzas Armadas. ${ }^{8}$ En ese sentido, la Iglesia Católica y las tres armas funcionaron como los principales espacios de nacionalización a partir de la década de 1930. Ambas instituciones guardaban una serie de afinidades centradas en el anti-liberalismo, el anticomunismo, la necesidad de defender al pueblo trabajador de los enemigos externos (reales e imaginarios, materiales y simbólicos). Este doble proceso de catolización y militarización de la sociedad argentina marcará las formas de pensar lo religioso y lo nacional entre 1930 y 1983, tanto durante períodos de gobiernos constitucionales como de dictaduras.

En este sentido, buena parte de los políticos que ocupó cargos hacia fines del siglo XX y comienzos del XXI nació, creció y se socializó inmersa en este universo de sentido permeado por las influencias del catolicismo integral. Para el caso de los senadores que ocuparon bancas entre 2001 y 2011, el año de nacimiento promedio es $1951^{9}$. Es decir que iniciaron su militancia política y social en los años sesenta y setenta, signados por la inestabilidad institucional, los repetidos golpes de Estado ${ }^{10}$, la debilidad de los partidos y un clima de creciente violencia política. En otras palabras, una etapa de fragilidad del régimen constitucional en la que la democracia representativa no era el sistema de gobierno por antonomasia y los partidos funcionaban de manera fragmentada y discontinua. Además, esta "crisis de legitimidad" tenía ya larga data en el país, pudiendo ubicarse sus inicios con el golpe de 1930, aunque se agudizara con el derrocamiento del peronismo en el $1955 .{ }^{11}$

Las senadoras cuyas trayectorias estudiamos aquí se socializaron políticamente en estos años, caracterizados por las interrupciones del orden democrático, la proscripción del peronismo y la represión estatal. A decir de Donatello, la debilidad de los partidos políticos en esas décadas, tanto a nivel de identidades como de redes institucionales, dejó vacante un lugar que ocuparon los grupos religiosos. ${ }^{12}$ Ante la relativa ausencia de espacios fuertes de socialización político-partidaria, buena parte de los intereses y actividades de quienes en el futuro se dedicarían a la política fueron canalizados en los múltiples ámbitos que ofrecía el catolicismo, habida cuenta de su multifacética

\footnotetext{
${ }^{8}$ Mallimaci, "Catolicismo y militarismo en la Argentina (1930-1983)".

${ }^{9}$ Gabriel Levita, “¿De patricios a plebeyos? Sociología de las elites políticas. El Senado y los senadores argentinos en la primera década del siglo XXI", Estudios Políticos 51. Universidad de Antioquia (2017): $13-35$.

${ }^{10}$ Entre 1930 y 1983 la historia política argentina registra seis golpes cívico militar religiosos que tuvieron lugar en los años 1930, 1943, 1955, 1962, 1966 y 1976. Debemos también sumarle los numerosos intentos de derrocamiento de gobiernos democráticos por parte de sectores de las Fuerzas Armadas, de los grupos económicamente dominantes, sectores de la Iglesia y otros actores. Además, es necesario considerar que aun durante gobiernos civiles electos por el voto popular estuvieron proscriptos en distintos momentos y por diferentes períodos las dos fuerzas políticas más importantes: el radicalismo y el peronismo.

${ }^{11}$ Manuel Mora y Araujo, "El ciclo político argentino”, Desarrollo Económico. 22 (86) (1982): 203-230.

${ }^{12}$ Luis Miguel Donatello, "Conflictividad política y conflictividad religiosa en la Argentina moderna: procesos de ‘teologización' de la política”, Sí, somos americanos. Revista de estudios transfronterizos. 8 (1) (2006): 95-96.
} 
penetración en el tejido social y, en ese sentido, de los variados y atractivos espacios que tenía para ofrecer. Diferentes opciones político-religiosas florecieron en esos años tanto a la izquierda como a la derecha del espectro político, pero siempre rechazando la legitimidad puramente partidaria desde una matriz en la que lo religioso y lo político se imbrican mutuamente. ${ }^{13}$

En la misma línea, Esquivel señala que la mayoría de los políticos argentinos de la actualidad ha sido socializado en una cultura católica y que, si bien muchos de ellos no cumplen gran parte de los preceptos religiosos, ese imaginario cristiano constituye un telón de fondo que brinda referencias simbólicas y, a menudo, una base de legitimidad política. Para interpretar esa dinámica el autor propone el concepto de laicidad subsidiaria como correspondiente a "un tipo de Estado que presenta una fuerte matriz católica en su génesis e historia, pero que los procesos de democratización y secularización han forjado novedosos reconocimientos a los formatos plurales de las sociedades contemporáneas". ${ }^{14}$

Entonces, si el factor religioso tiene un peso considerable en las socializaciones y sociabilidades de los políticos argentinos y en sus inicios en la política ¿de qué manera se vincula con sus discursos y votaciones en el parlamento? ¿Qué lugar puede llegar a ocupar en determinados debates en los que existe una posición institucional de la Iglesia? Para adentrarnos en este análisis sobre los vínculos y solapamientos entre religión y política en la Argentina contemporánea, reconstruimos las trayectorias de Díaz y Negre de Alonso. Cada una votó de manera opuesta, pero fundamentando ambas su decisión con argumentos religiosos.

Desde el punto de vista metodológico, entendemos al análisis de trayectorias sociales en el marco de los estudios biográficos, que buscan analizar las experiencias de la vida de una persona a partir de fuentes primarias o secundarias. ${ }^{15}$ La reconstrucción de una trayectoria indaga acerca de las socializaciones, espacios de sociabilidad y recorridos de los actores en distintos ámbitos de su vida, como el familiar, educativo, asociativo, laboral, religioso, entre otros. Las particularidades del trabajo de campo con elites políticas, entre las que contamos las dificultades de acceso a los actores y un fuerte control de la imagen que quieren dar de sí mismos, ${ }^{16}$ nos llevaron a valernos de una pluralidad de fuentes secundarias y, cuando fue posible, de una entrevista en profundidad.

${ }^{13}$ Humberto Cucchetti, Combatientes de Perón, herederos de Cristo. Peronismo, religión secular y organizaciones de cuadros (Buenos Aires: Prometeo, 2010); Luis Miguel Donatello, Catolicismo y Montoneros: religión, política y desencanto (Buenos Aires: Manantial, 2010)

${ }^{14}$ Esquivel, "Religious and Politics in Argentina".141. Traducción propia del original en inglés.

15 John W, Creswell. Qualitative Inquiry and Research Design: Choosing Among Five Approaches (SAGE, Thousand Oaks, 2012) 282; Fortunato Mallimaci y Verónica Giménez Béliveau, "Historia de vida y métodos biográficos", Estrategias de investigación cualitativa, coord. Irene Vasilachis de Gialdino (Barcelona: Gedisa, 2006) 175-212.

${ }^{16}$ Máximo Badaró y Virginia Vecchioli, "Algunos dilemas y desafíos de una antropología de las elites", Etnografias Contemporáneas, año 4, 4 (2009): 7-20; Gabriel Levita, “¿Qué pretende usted de mí?’ Enfrentando obstáculos en las entrevistas a elites en una investigación sobre los senadores nacionales argentinos", Revista Latinoamericana de Metodología de las Ciencias Sociales 8.1, Universidad Nacional de La Plata, (en prensa). 


\section{Sociabilidades religiosas en dos trayectorias: convergencias y divergencias}

María Rosa Díaz ${ }^{17}$ nace en 1953 en Firmat, provincia de Santa Fe, una localidad de menos de veinte mil habitantes en una de las zonas agrícolas más productivas de la pampa húmeda. Su madre era ama de casa y su padre encargado en una tienda del pueblo. Por impulso de la madre, la educación de María Rosa tuvo un fuerte contenido religioso y asistió a la Escuela Virgen de la Merced.

En 1971 María Rosa se muda a la ciudad de Rosario para estudiar Letras en la universidad nacional. Allí se hospeda en un pensionado de monjas y conoce en las aulas a Rubén, quien sería su primer marido y padre de su hija mayor. Juntos ingresan al PRT-ERP (Partido Revolucionario de los Trabajadores - Ejército Revolucionario del Pueblo) como militantes, pero, mientras Rubén se involucra en las acciones armadas, María se dedica a la parte de prensa y propaganda y a trabajar en grupos de base que constituían el costado legal y visible de la organización. También hacía de transporte y de correo entre militantes.

Sin embargo, vivieron poco tiempo en Rosario, ya que en el año 76 tras el golpe de Estado y el recrudecimiento de la represión, la pareja y su hija recién nacida escapan a Comodoro Rivadavia, provincia del Chubut, en donde tenían a una familiar. Al poco tiempo él retorna a Rosario y es asesinado. A partir de entonces, María Rosa comenzará un largo exilio interno junto a su hija que la llevará luego a Canals, a Villa Carlos Paz, a Córdoba capital en donde conoce a quien sería su segundo marido. Siempre trabajando como empleada doméstica y niñera, a fines de los años ochenta se va a vivir a Ushuaia.

En el año 90 ingresa como preceptora en un colegio secundario público de la capital fueguina y al poco tiempo comienza a organizar junto con colegas la actividad sindical en su lugar de trabajo. De allí surge el SUTEF (Sindicato Único de Trabajadores de la Educación Fueguina) con peronistas, radicales y militantes de diversas corrientes de la izquierda. Permanecen dentro de la esfera de ATE-CTA (Asociación de Trabajadores del Estado-Central de Trabajadores Argentinos) y conforman junto a otros dirigentes un proyecto político-electoral que toma las estructuras disponibles del ARI fueguino sin tener mayores compromisos con la conducción nacional de ese partido, que luego pasaría a conformar la Coalición Cívica bajo el mando de Elisa Carrió. Triunfan en las elecciones de 2007 ganando la gobernación y las dos bancas de senadores por la mayoría, la segunda de las cuales ocupa Díaz hasta 2013. Para 2009 ya se habían separado del ARI y conformado un espacio político provincial y un bloque legislativo propios.

\footnotetext{
${ }^{17}$ Caso desarrollado a partir de entrevista a María Barón, Directorio legislativo. Quiénes son nuestros legisladores y cómo nos representan: Congreso de la Nación Argentina 2010-2011 (Buenos Aires: Fundación Directorio Legislativo, 2010); Honorable Cámara de Senadores de la Nación. Listado de Senadores en http://www.senado.gov.ar/senadores/listados/listaSenadoRes (fecha).
} 
Por su parte, Liliana Teresita Negre ${ }^{18}$ nace en 1954 en San Luis capital en el seno de una familia tradicional católica practicante. Se recibe de abogada en la UBA en 1976 -siendo además auxiliar docente de la cátedra de Derecho Constitucional- y retorna a su provincia natal para ejercer el derecho en el ámbito privado en la localidad puntana de Villa Mercedes, donde llega a crear el estudio jurídico Alonso Negre, junto a su esposo Mario Alonso. Su carrera en el mundo judicial comienza en 1981 al ser nombrada jueza en lo civil, comercial y minas de Villa Mercedes a la temprana edad de veintisiete años.

En paralelo, comienza su activismo en el mundo de las asociaciones profesionales de abogados en el que pasaría por las vicepresidencias del Colegio de Magistrados y Funcionarios de la Segunda Circunscripción Judicial (1981-83) y del Colegio de Abogados y Procuradores de la Ciudad de Villa Mercedes (1987-89), del que también sería presidenta entre el 89 y el 91 y pro-secretaria de la comisión directiva de la Federación Argentina de Colegios de Abogados (FACA) entre el 90 y el 92. La vuelta a Buenos Aires se da en 1990 cuando ingresa a la docencia universitaria como ayudante de segunda en Derecho Comercial III de la UBA, al tiempo que hace una maestría en derecho empresarial en la Universidad Austral (UA) y publica un libro sobre legislación comercial. ${ }^{19}$ Obtiene el título en 1993 y, nuevamente, vuelve a su provincia donde ahora se vuelca a la vida académica como profesora adjunta de derecho comercial en la Universidad Nacional de San Luis. Su gran ascenso se da en 1996 cuando, durante la cuarta gobernación de Adolfo Rodríguez Saá, es nombrada a cargo de la Fiscalía de Estado de la provincia, mismo puesto que llegaría a ocupar su esposo años más tarde. En los intervalos entre los dos cargos ejerce además como abogada en el estudio familiar.

Después de su posgrado en la UA comienza a circular dando cursos y conferencias y asistiendo a jornadas y congresos en diversas instituciones universitarias católicas alrededor del mundo, algunas de ellas ligadas al Opus Dei, del que Negre forma parte desde 1996. Por ejemplo, la Universidad de Navarra, la Universidad CEU San Pablo de Madrid, la Santo Tomás de Santiago de Chile. Primero sobre derecho comercial, que es su especialidad originaria, y después del año 2000 también sobre temáticas pro-vida y pro-familia.

Para esa época conduce durante 1994 el programa Ritmo Empresario, que trata temas de actualidad jurídica y económica desde el punto de vista empresarial. También da clases en la Universidad FASTA, en posgrados de la UA y de la Universidad Católica

\footnotetext{
${ }^{18}$ Caso desarrollado a partir de María Barón, Directorio legislativo. Quiénes son nuestros legisladores y cómo nos representan: Congreso de la Nación Argentina 2010-2011 (Buenos Aires: Fundación Directorio Legislativo, 2010); Honorable Cámara de Senadores de la Nación. Listado de Senadores en http://www. senado.gov.ar/senadores/listados/listaSenadoRes (31/10/210); Eduardo Tagliaferro, "Una chica de familia", Página/12, (Buenos Aires) edición impresa, 4 de septiembre de 2005.

${ }^{19}$ Liliana Teresita Negre de Alonso, Los acreedores laborales en el proceso concursal (Santa Fe: RubinzalCulzoni, 1992). Luego seguido por dos más: Liliana Teresita Negre de Alonso, Contratos Laborales en la Quiebra (Santa Fe: Rubinzal-Culzoni, 2001); Liliana Teresita Negre de Alonso, Reformas a la Ley de Concursos-Ley 26.086 (Santa Fe: Rubinzal-Culzoni, 2006).
} 
de Cuyo y es miembro correspondiente del Instituto de la Empresa de la Academia Nacional de Derecho y Ciencias Sociales de Córdoba.

Independientemente de su contenido doctrinal y de las interpretaciones religiosas que promuevan, resaltamos que el Opus Dei funciona como un espacio de socialización católica para las clases altas en el que distintas personas se encuentran, toman conocimiento de sus compañeros y establecen vínculos que luego tienen efectos en otras actividades.$^{20} \mathrm{Al}$ igual que otros grupos, las redes sociales aquí formadas pueden movilizarse y tener efectos en las vidas profesionales de sus miembros. En este caso en particular, se trata de un espacio muy fuertemente transnacionalizado.

Así, entre el derecho comercial y el de familia se vincula a numerosas redes y espacios pro-vida en el país y en el exterior. En el ámbito nacional, sus actividades académicas tienen lugar, además de en la UA, en la Universidad Católica de Cuyo, la Universidad Católica de La Plata y la Universidad Católica Argentina, entre otras. En este sentido, recibe varios premios y reconocimientos de diversas asociaciones católicas de San Luis, la Argentina y otros países por sus posiciones en el congreso.

En 1999 es nombrada vicedecana de la Facultad de Derecho de la UA, cargo que ocupará hasta 2001. También ese año se candidatea a diputada nacional por el PJ de San Luis, pero no le alcanzan los votos para ingresar. Sí lo hace en 2001 como primera candidata a senadora, cargo en el que es reelegida en 2005 y en 2011 siempre acompañando a la familia Rodríguez Saá. Finalizó su mandato en 2017 sin renovar la banca ni acceder a otro cargo. El debate sobre la ley del matrimonio igualitario la encontró formando parte del Interbloque Federal.

El desarrollo de estas dos trayectorias delinea una serie de puntos en común y de diferencias en torno al peso de lo religioso. El recorrido de Díaz, así, aparece permeado por una socialización religiosa desde la familia y la escuela y por la participación en espacios de sociabilidad ligados al catolicismo: el colegio de mojas, su grupo de amigas, el pensionado, el ingreso a la militancia política. No obstante, su trayectoria posterior se desarrolla al margen de instituciones religiosas. En el caso de Negre, proviene de una familia católica practicante y tradicional de San Luis en donde los espacios de socialización y sociabilidad religiosos también se encuentran ampliamente extendidos. Su diferencia principal se encuentra en que a partir de un momento de su carrera profesional a mediados de la década de 1990 se vincula activamente a organizaciones ligadas a las redes transnacionales del Opus Dei.

En este sentido, otra diferencia entre ambas trayectorias podemos situarla sobre la tensión entre lo local y lo transnacional. En el caso de Díaz tenemos ante nosotros un recorrido con un fuerte arraigo local en la cual las principales experiencias de vida de la senadora pasan por una socialización y por instancias de sociabilidad locales. En primer lugar, la infancia en el pueblo y en la escuela de monjas en el seno de una

\footnotetext{
${ }^{20}$ Luis Miguel Donatello, "Catolicismo y elites en la Argentina del siglo XXI: individualización y heterogeneidad”, Estudios sociológicos 29.87 (2011): 840.
} 
familia de sectores medios bajos. Después del breve paso por la universidad y la militancia, nuevamente la vida en ciudades más pequeñas. Luego, ya como preceptora y, más aun como sindicalista, se abren espacios de sociabilidad donde poner además en práctica algunos elementos de la socialización política de la juventud.

Por su parte, en la trayectoria de Negre encontramos una transnacionalización de la mano de redes académico-militantes donde lo religioso cumple un papel clave. Luego del posgrado en la UA se inserta en grupos y eventos jurídicos de carácter internacional ligados a las redes del Opus Dei. Después del vicedecanato, esas intervenciones continúan produciéndose en diversos países, pero ya no tanto sobre cuestiones de derecho comercial, sino ahora sobre la familia, la concepción y el inicio de la vida.

En ambas trayectorias constatamos el peso de socializaciones y sociabilidades religiosas, aunque operando de diferente manera. Esta comparación entre los dos recorridos permite vislumbrar la pluralidad de formas y modos de solapamiento entre lo religioso y lo político. En distintos momentos de sus vidas y en diferentes ámbitos de las mismas las socializaciones y sociabilidades religiosas se encuentran presentes y permiten que nos preguntemos por sus efectos en la arena política. Para ello nos adentramos en sus intervenciones parlamentarias en ocasión del debate estudiado, de forma tal de pensar las relaciones entre sus trayectorias y sus discursos.

\section{El debate sobre el matrimonio igualitario en el Senado: fundamentaciones religiosas y no religiosas}

El debate que tuvo lugar en el Senado durante la sesión de los días 14 y 15 de julio de 2010 en la que se aprobó el matrimonio para parejas del mismo sexo permite estudiar una serie de representaciones movilizadas por las dos senadoras en dicha oportunidad. El debate previo al tratamiento y la posterior sesión en que se sancionó la ley tuvieron amplia repercusión en la prensa y en la opinión pública en general, con grupos a favor y en contra y la fuerte oposición institucional tanto de la Iglesia Católica ${ }^{21}$, como de otras iglesias y grupos religiosos ${ }^{22}$. Los argumentos esgrimidos tanto a favor como en contra del proyecto presentado abrevaron en distintos imaginarios y sentidos comunes $\mathrm{y}$, al mismo tiempo, en los más diversos campos y tradiciones del derecho civil, la filosofía política y la religión.

En este sentido, los solapamientos y cruces entre legitimaciones políticas y religiosas han sido característicos en los discursos políticos en la Argentina, tanto en el marco de discusiones sobre la cuestión social o el pasado reciente ${ }^{23}$ como acerca de debates en

\footnotetext{
${ }^{21}$ La principal figura pública de la campaña de la Iglesia en contra de la ley fue el entonces arzobispo de Buenos Aires Jorge Bergoglio, a la postre Papa Francisco.

22 Marcos A. Carbonelli y Otros. "Religión, sexualidad y política en la Argentina: intervenciones católicas y evangélicas en torno al aborto y el matrimonio igualitario", Revista del Centro de Investigación 9.36 (2011): 25-43.

${ }^{23}$ Juan Eduardo Bonnin, "From discursive event to discourse événement: A case study of political-religious discourse in Argentina", Discourse \& Society 22.6 (2011): 677-692. Juan Eduardo Bonnin, "Scenes of
} 
torno a temáticas ligadas a sexualidad, salud y reproducción. ${ }^{24}$ Dentro de estos últimos, otros trabajos académicos sobre la cuestión ya destacan los complejos vínculos entre lo religioso y lo político a partir de las intervenciones de los legisladores en el debate por el matrimonio igualitario. ${ }^{25}$

Aquí nos interesa analizar las justificaciones de los votos de Díaz y Negre, a favor y en contra de la iniciativa, respectivamente. ${ }^{26}$ La primera, al igual que otros legisladores, se apoyó en alusiones explícitas a sus creencias religiosas para fundamentar su apoyo a la ley.

Incluso, varios sacerdotes han reivindicado que para Jesús, el reino de misericordia, justicia e inclusión de los desplazados de su pueblo estaba por encima de toda otra concepción y valores culturales de su tiempo -la familia incluida- y se han preguntado cómo podríamos considerarnos discípulos de Jesús sin conmovernos con entrañas de misericordia ante los hermanos y hermanas excluidos del camino de la vida y la igualdad ante la ley. ¿Podemos seguir de largo sin detenernos a escuchar lo que Dios nos está queriendo decir a través de tantos y tantas que se sienten explotados y deprimidos bajo un sistema discriminatorio ${ }^{27}$

Esta analogía teológico-política resulta en una interpretación de la Biblia en la que quienes eran los pobres a los que Jesús prometía el reino de los cielos en el texto sagrado, son aquí los "excluidos" de la igualdad ante la ley. Se identifica a los pobres con los excluidos y a estos con aquellos a quienes les son negados derechos. Así, se legitima la propia postura comparando lo que debería hacer el Senado (votar afirmativamente) con lo que hizo Jesús frente a sus acólitos. Asimismo, esta lectura de la Biblia se corresponde con ciertas corrientes del catolicismo que han leído estos pasajes bíblicos en clave de acción política ligada a posturas tercermundistas.

Explicit Catholicism: The Pope and the Political Meanings of Religion in Argentina", Journal of Latin American Cultural Studies 22.2 (2013): 123-138.

${ }^{24}$ Gabriela Irrazábal, "Religión y salud: la intervención pública de agentes religiosos católicos formados en bioética en el debate parlamentario sobre la muerte digna en la Argentina”, Salud Colectiva 11.3 (2015): 331-349; Carbonelli, Mosqueira y otros, "Religión, sexualidad y política en la Argentina: intervenciones católicas y evangélicas en torno al aborto y el matrimonio igualitario".

${ }^{25}$ María Candelaria Sgró Ruata y Juan Marco Vaggione, "Las marcas de lo religioso en la política sexual: debate legislativo y matrimonio entre personas del mismo sexo en Argentina", Soc. e Cult. (Goiânia) 15.2 (2012): 331-345; Juan Marco Vaggione y Daniel Jones, "La política sexual y las creencias religiosas: el debate por el matrimonio para las parejas del mismo sexo (Argentina, 2010)", Revista de Estudios Sociales.51 (2014): 105-117; Juan Marco Vaggione, "Sexual Rights And Religion: Same-sex Marriage And Lawmakers' Catholic Identity In Argentina”, University of Miami Law Review 65.3 (2011): 935-954; Levita, "Política y religión en el Senado argentino".

${ }^{26}$ En otros debates ligados a temáticas de sexualidad, salud y reproducción las senadoras se comportaron de manera similar. En la votación de la Ley de Identidad de Género (9/5/2012), según la cual las personas pueden pedir que se cambie el género con el que figuran inscriptos en el Registro Nacional de las Personas de acuerdo con su autopercepción, Díaz voto afirmativamente y Negre de Alonso se ausentó. En el tratamiento de la Ley de Reproducción Médicamente Asistida (24/4/2013) Díaz votó por la afirmativa y Negre de Alonso por la negativa.

${ }^{27}$ Díaz en Honorable Cámara de Senadores de la Nación. Versión taquigráfica, $14^{\circ}$ Reunión- $9^{\circ}$ Sesión ordinaria, 14 y 15 de julio de 2010 en [http:/www.senado.gov.ar/parlamentario/parlamentaria/actas]. 
Ahora bien, estas representaciones religiosas no impiden también una justificación sustentada en un principio de escisión que es propio del paradigma de la modernidad y del desarrollo de las tendencias centrales de la jurisprudencia más influida por la corriente liberal y positivista.

Hace 122 años, con la instauración del matrimonio civil, en clara búsqueda de la inclusión de las minorías, la Iglesia utilizó los mismos argumentos que en este momento, tomando a la medida como el fin de la familia en contra del orden natural con resultados funestos en la sociedad. No debería estar en discusión lo religioso. Pero es válido recordar que existe en la Argentina una división explícita entre Iglesia y Estado. Si bien el artículo $2^{\circ}$ de nuestra Constitución Nacional reconoce el culto católico, apostólico y romano, no se trata de una religión de estado y no todos deben profesarla. No hay ningún tipo de unión moral entre el estado constitucional de derecho y la religión católica que permita trasladar los contenidos de dicha religión a la sociedad civil en términos de regulación de derechos, sostuvo el doctor Andrés Gil Domínguez en este palacio en la Comisión de Legislación General. ${ }^{28}$

Así, la separación entre lo religioso y lo civil fue el eje de varias de las argumentaciones a favor del proyecto a votar. Se trata de una vuelta al principio de separación entre la Iglesia y el Estado y a la norma de que el espacio de las creencias debe permanecer en el fuero personal de los individuos, mientras que los asuntos públicos como los contratos (matrimonial, en este caso) deben estar regulados bajo la égida de la jurisprudencia.

Por su parte, las intervenciones de Negre, quien fue además miembro informante del dictamen de comisión que rechazaba el proyecto, formaron parte del grupo de quienes se opusieron a la norma movilizando significados ligados al derecho natural y la familia. En este sentido, su exposición apuntó a poner en cuestión, o al menos a debilitar, la separación entre el Estado y la Iglesia propia de la modernidad.

Si nosotros nos queremos olvidar absolutamente de la religión o mirar desde el positivismo las limitaciones y las regulaciones, veremos que en casi todos los códigos penales del mundo están penados el hurto, el homicidio, la violación, los abusos sexuales. De hecho, si vamos al origen de la religión judeocristiana, los Diez Mandamientos no hacen ni más ni menos que penar: no robarás, no cometerás adulterio, no violarás, etcétera. $\mathrm{O}$ sea que por más que queramos separarlos llega un momento en que por nuestra misma historia y nuestra misma tradición tienen un argumento en común. En consecuencia, el pasaporte al debate es la razonabilidad intrínseca de los argumentos. No en nombre del liberalismo podemos destruir las propias libertades sino que, desde las convicciones de cada uno, en el ámbito público debemos verter nuestros argumentos inteligibles al hombre común para que los comprenda y para que la comunidad en su conjunto pueda caminar hacia la construcción del bien común. ${ }^{29}$

\footnotetext{
${ }^{28}$ Díaz en Honorable Cámara de Senadores de la Nación. Versión taquigráfica, $14^{\circ}$ Reunión- $9^{\circ}$ Sesión ordinaria.

${ }^{29}$ Negre de Alonso en Honorable Cámara de Senadores de la Nación. Versión taquigráfica, $14^{\circ}$ Reunión- $9^{\circ}$ Sesión ordinaria.
} 
Al señalar una continuidad entre el derecho religioso de la tradición judeocristiana y el derecho positivo de los modernos Estados-nación se cuestionan los principios básicos de la laicidad y se argumenta que la legislación no debe contradecirse con las normas y reglamentaciones religiosas que le son cronológicamente anteriores. Es decir, existiría una superioridad moral de las normas religiosas por sobre los códigos legales, puesto que estos no serían otra cosa que un derivado de aquellas.

Asimismo, la idea de que las creencias personales deben volcarse en el debate público supone un cuestionamiento de los principios liberales de separación ente lo público y lo privado, siendo este último ámbito el terreno al que debería reservarse lo religioso según este punto de vista. La idea de "construcción del bien común" también tiene reminiscencias a los principios de la doctrina social de la Iglesia Católica y su concepción de lo social en términos de comunidad.

Los diez pecados capitales de la ley: Introducir el matrimonio homosexual en un sistema jurídico pensado para un matrimonio heterosexual. (...). Pretender dar iguales efectos a uniones que son diferentes y cuya diversidad es la base del matrimonio argentino, sin modificar el resto de la ley. Equiparar los efectos de las uniones utilizando un lenguaje neutro. Determinar que son hermanos bilaterales los que proceden del mismo padre, dejando de lado la tradicional definición según la cual son hermanos bilaterales los que proceden del mismo padre y madre, sin advertir que los hermanos bilaterales no pueden proceder del mismo padre porque dos hombres en conjunto no pueden concebir. Establecer el parentesco colateral sólo por línea paterna, a partir de los abuelos y bisabuelos, haciendo desaparecer inexplicablemente las relaciones con las abuelas y las bisabuelas. Dar en lo relativo al apellido de casadas mejores derechos a las mujeres que deciden formar parejas homosexuales que a aquellas que se casan con un hombre, porque las primeras pueden optar por el apellido de la familia, mientras que las segundas, o sea las heterosexuales, no.

Otorgar un régimen más beneficioso para las lesbianas que para las mujeres que contraigan nupcias heterosexuales respecto del apellido de los hijos, porque las lesbianas pueden dar el primer apellido a sus hijos, mientras que los hijos menores unidos en matrimonio heterosexual llevan siempre el apellido paterno. Establecer un sistema más beneficioso a los hombres unidos en matrimonio homosexual que a quienes se casan con una mujer en lo que respecta a la tenencia de los hijos menores de cinco años. No reformar el régimen de presunciones de paternidad y de maternidad que se estructura en base a la diferencia sexual, a diferencia de todas las legislaciones del mundo que no aplican iguales efectos a los matrimonios hetero que a los homosexuales. Dar mejores derechos sucesorios a los matrimonios de lesbianas y homosexuales que a los matrimonios heterosexuales. ${ }^{30}$

La reformulación es un procedimiento básico de los géneros de predicación que considera que existe un texto fuente autorizado a partir del cual se elabora otro texto que busca la legitimidad de su relación con el primero. En su variante imitativa, la reformulación toma la forma de un texto concreto y la utiliza en la construcción de

\footnotetext{
${ }^{30}$ Negre de Alonso en Honorable Cámara de Senadores de la Nación. Versión taquigráfica, $14^{\circ}$ Reunión- $9^{\circ}$ Sesión ordinaria.
} 
uno nuevo. ${ }^{31}$ Aquí, la senadora utiliza dos fuentes. Por un lado, los diez mandamientos que, de acuerdo con la tradición judeocristiana, Dios entregó a Moisés en el Monte Sinaí como decálogo sagrado para regir las conductas humanas. Por el oro, los siete pecados capitales que el cristianismo y la propia Iglesia Católica tipifican y sancionan. Así, tenemos los "diez pecados capitales" en los que incurriría esta ley.

Ahora bien, tras estas declaraciones se vuelve sobre un principio básico del liberalismo y del derecho liberal; las conductas privadas que no dañen a terceros no pueden ser penadas. La justificación religiosa se complementa con un recurso legitimador desde el punto de vista jurídico.

No me preocupa que las personas homosexuales, si se quieran casar, se casen, sino el efecto sobre terceros. ${ }^{32}$

Recapitulando, del análisis de estas intervenciones en el debate surge que lo religioso aparece como justificativo tanto de un voto a favor como de uno en contra. A su vez, argumentos jurídicos también fueron esgrimidos transversalmente. Esto supone cuestionar cierto sentido común que da por hecho que aquellos que se opusieron al proyecto lo hicieron basados en convicciones religiosas, mientras que quienes lo apoyaron lo hicieron desde un discurso laicista o "anti-religioso".

En ambos casos observamos la movilización de una pluralidad de argumentos religiosos como legitimadores del voto, aun cuando su postura fuera diametralmente opuesta. Las interpretaciones bíblicas e históricas en torno al catolicismo aparecen entonces abundantemente, aunque movilizadas en direcciones opuestas. Junto a este tipo de justificaciones también encontramos referencias jurídicas que persiguen sustentar la postura de cada senadora apoyándose mutuamente con las alusiones religiosas.

Incluso con las diferencias señaladas en las trayectorias de cada una, la interpretación de la situación aparece mediada por una matriz religiosa. Esto se da en el caso de Negre, cuya inserción en organizaciones religiosas ya señalamos, pero también en el de Díaz, en donde este rasgo se encuentra ausente.

En los espacios ligados al catolicismo por el que las actoras pasan existen significados en disponibilidad que los actores interiorizan y de los que se apropian creativamente de distintas maneras dándoles un cariz particular y cambiante de acuerdo a su biografía personal y a su actividad política, pero siempre circunscriptos dentro de los horizontes de posibilidad y sentido que formaron parte de su experiencia de vida. Los universos de sentido religioso disponibles constituyen entonces fuentes de referencias simbólicas para interpretar problemas de la realidad y fundamentar las posturas de los actores frente a ellos. De allí la abundancia de alusiones al respecto, al igual que las

\footnotetext{
31 Arnoux, Elvira. "La reformulación interdiscursiva en "Análisis del discurso"”. Ponencia presentada en el $V$ Congreso Nacional de Investigaciones Lingüísticas y Filológicas (Lima: Universidad Ricardo Palma, 2004).

${ }^{32}$ Negre de Alonso en Honorable Cámara de Senadores de la Nación. Versión taquigráfica, $14^{\circ}$ Reunión- $9^{\circ}$ Sesión ordinaria.
} 
que podemos encontrar en los discursos de muchos otros legisladores que participaron de ese debate.

A su vez, lo religioso aparece como garante pretendido de una legitimidad trascendente a la política. En los dos casos analizados, la propia postura busca quedar fortalecida al impregnarse de un valor extra-político, en el que la justificación contraria o favorable a la ley es presentada en términos teológico-políticos. La variante más clara, es la del caso de Negre, quien participa también del debate como representante de las redes "pro-familia" y "pro-vida" a las que pertenece. Sin embargo, las argumentaciones de carácter religioso están presentes en las dos intervenciones y no solo en la de quien milita en organizaciones católicas, como podríamos suponer a priori. Esto nos devuelve sobre el peso de las socializaciones y sociabilidades religiosas en la Argentina del siglo XX, que permite que lo religioso permee los discursos de los legisladores, incluso de quienes no participan en organizaciones católicas ni se consideran practicantes.

\section{Conclusiones}

Tanto desde la sociología como desde la ciencia política, a menudo se ha relegado el papel de lo religioso en las dinámicas políticas de las sociedades contemporáneas. Sin embargo, diversos autores han dado cuenta del modo en que el papel subordinado, rezagado y crecientemente irrelevante que las teorías clásicas de la secularización asignaban a la religión finalmente no se verifica en la realidad. ${ }^{33}$ Pensar los efectos de la modernidad sobre la religión en nuestras realidades contemporáneas invita a cuestionar la utilización de modelos explicativos como el de la modernización. En este sentido, entender a la secularización como parte del proyecto de la modernidad tendiente a la desaparición o debilitamiento de lo religioso, nos devolvería a los supuestos analíticos que obligan a reflexionar en términos de "atraso" o "desvío".

Hervieu-Léger propone una definición de la secularización que se aparta de la matriz evolucionista al plantear una reconfiguración de lo religioso que habilita la conceptualización de los distintos procesos de diversificación y pluralización. Así, "la secularización no consiste en la desaparición de la religión confrontada a la modernidad: es el proceso de reorganización constante del trabajo religioso en una sociedad estructuralmente impotente para satisfacer las expectativas que debe suscitar para existir como tal". ${ }^{34}$

La misma autora ha hecho hincapié en la idea de memoria y en el modo en que esta es construida por diversos grupos en referencia a un pasado mitificado. La definición

\footnotetext{
33 José Casanova, "Religiones públicas y privadas", Caja de herramientas. El lugar de la cultura en la sociología norteamericana, comp. Javier Auyero (Buenos Aires: Universidad Nacional de Quilmes, 1999); Ari Pedro Oro, "Consideraçoes sobre a modernidade religiosa", Sociedad y Religión. 14/15 (1996): 61-70.

${ }^{34}$ Danièle Hervieu-Léger, Vers un nouveau christianisme. Introduction à la sociologie du christianisme occidental (Paris: Éditions du Cerf, 1987) 227.
} 
de identidades en torno a la creación de linajes se inscribe así en luchas por imponer definiciones legítimas sobre la religión y sus instituciones. ${ }^{35}$

A partir de la reconstrucción de las dos trayectorias y del análisis de las intervenciones de las dos senadoras en el debate estudiado, los significados religiosos ligados al catolicismo aparecen como fuente de referencias simbólicas y de legitimación de las posturas políticas, emergiendo de un modo transversal a los votos de los senadores. Sus influencias no son unívocas ni se manifiestan de igual manera, sino que constituyen un universo plural, heterogéneo y en disponibilidad. Diversos son los significados invocados como diversos son los actores que los movilizan. Al mismo tiempo, conviene recordar que la presencia de estos sentidos en el debate político no se limita al terreno de las alegorías o a las discusiones teológicas, sino que se encuentra también inmerso en luchas organizadas en torno a intereses colectivos sobre el control de bienes materiales y simbólicos.

La idea de laicidad subsidiaria pensada para el caso argentino supone la coexistencia del reconocimiento estatal de nuevos derechos e identidades en un marco de mayor pluralismo y creciente secularización junto con la persistencia de lógicas institucionales que ubican a la Iglesia Católica en un lugar privilegiado como interlocutora e intermediaria a la hora de la aplicación de políticas públicas. ${ }^{36}$ Ahora bien, esa matriz católica presente en buena parte de las instituciones estatales no supone, como vimos, una traducción mecánica de las posturas institucionales adoptadas por la Iglesia, cuya efectividad para transformarse en legislación y en políticas públicas, en este caso concreto, fue puesta en entredicho. Antes bien, se trata de la vigencia de las socializaciones y sociabilidades religiosas ligadas a los diversos espacios del catolicismo que poseen las elites políticas argentinas y de las que dimos cuenta en este artículo. Esta pluralidad permite la coexistencia de intereses contradictorios y la movilización de significados en direcciones opuestas, que pueden o no coincidir con las posturas institucionales de la Iglesia. Junto con una multiplicidad de otros factores socio-históricos y coyunturales, dichas dinámicas contribuyen a entender el tipo de articulación compleja entre religión y política en la Argentina contemporánea.

\section{Bibliografía}

\section{Fuentes primarias}

\section{Prensa}

Página/12 (Buenos Aires) edición impresa 2005.

\footnotetext{
${ }^{35}$ Danièle Hervieu-Léger, "Catolicismo: el desafío de la memoria”, Sociedad y Religión.14/15 (1994): 9-28.

${ }^{36}$ Esquivel, "Religious and Politics in Argentina. Religious influence on parliamentary decisions on sexual and reproductive rights".
} 
Trayectorias sociales y legitimidades politico-religiosas en el Senado argentino a comienzos...

\section{Entrevistas}

Entrevista de Gabriel Levita a María Rosa Díaz, Buenos Aires, Argentina, 3 de marzo y 18 de mayo de 2010.

\section{Libros}

Barón, María. Directorio legislativo. Quiénes son nuestros legisladores y cómo nos representan: Congreso de la Nación Argentina 2010-2011. Buenos Aires: Fundación Directorio Legislativo, 2010.

Negre de Alonso, Liliana Teresita. Contratos Laborales en la Quiebra. Santa Fe: Rubinzal-Culzoni, 2001.

Negre de Alonso, Liliana Teresita. Los acreedores laborales en el proceso concursal. Santa Fe: Rubinzal-Culzoni, 1992.

Negre de Alonso, Liliana Teresita. Reformas a la Ley de Concursos-Ley 26.086. Santa Fe: Rubinzal-Culzoni, 2006.

\section{Publicaciones en Internet}

http://www.senado.gov.ar/senadores/listados/listaSenadoRes (2010)

http://www.senado.gov.ar/parlamentario/parlamentaria/actas (2010)

\section{Fuentes secundarias}

\section{Libros}

Creswell, John W. Qualitative Inquiry and Research Design: Choosing Among Five Approaches. SAGE: Thousand Oaks, 2012.

Cucchetti, Humberto. Combatientes de Perón, herederos de Cristo. Peronismo, religión secular y organizaciones de cuadros. Buenos Aires: Prometeo, 2010.

Donatello, Luis Miguel. Catolicismo y Montoneros: religión, política y desencanto. Buenos Aires: Manantial, 2010.

Hervieu-Léger, Danièle. Vers un nouveau christianisme. Introduction à la sociologie du christianisme occidental. Paris: Éditions du Cerf, 1987.

Martínez, Ignacio. Una nación para la Iglesia argentina. Construcción del Estado y jurisdicciones eclesiásticas en el siglo XIX. Buenos Aires: Academia Nacional de la Historia, 2013. 


\section{Capítulos de libro}

Casanova, José. "Religiones públicas y privadas". Caja de herramientas. El lugar de la cultura en la sociología norteamericana. Comp. Javier Auyero. Buenos Aires: Universidad Nacional de Quilmes, 1999.

Cucchetti, Humberto y otros. "Caminos sinuosos: nacionalismo y catolicismo en la Argentina contemporánea". El altar y el trono. Ensayos sobre el catolicismo político latinoamericano. Eds. A. Rivero y F. Colom González. Barcelona: Antrophos / Unibiblos, 2006.

Mallimaci, Fortunato y Giménez Béliveau, Verónica. "Historia de vida y métodos biográficos". Estrategias de investigación cualitativa. Coord. Irene Vasilachis de Gialdino. Barcelona: Gedisa, 2006.

Mallimaci, Fortunato, "El catolicismo argentino desde el liberalismo integral a la hegemonía militar". 500 años de cristianismo en Argentina, AA. VV. Buenos Aires: CEHILA, 1997.

\section{Artículos de revista}

Badaró, Máximo y Vecchioli, Virginia. "Algunos dilemas y desafíos de una antropología de las elites”. Etnografías Contemporáneas, año 4.4 (2009): 7-20.

Bonnin, Juan Eduardo. "From discursive event to discourse événement: A case study of political-religious discourse in Argentina". Discourse \& Society 22.6 (2011): 677-692.

Bonnin, Juan Eduardo. "Scenes of Explicit Catholicism: The Pope and the Political Meanings of Religion in Argentina". Journal of Latin American Cultural Studies 22.2 (2013): 123-138.

Bourdieu, Pierre. "Une interprétation de la théorie de la religion selon Max Weber". Archives européennes de sociologie 12 (1971): 3-21.

Carbonelli, Marcos A. y otros. "Religión, sexualidad y política en la Argentina: intervenciones católicas y evangélicas en torno al aborto y el matrimonio igualitario". Revista del Centro de Investigación 9.36 Universidad La Salle (2011): 25-43.

Di Stefano, Roberto. "La excepción argentina. Construcción del Estado y de la Iglesia en el siglo XIX”. Procesos: revista ecuatoriana de historia. 40 (2014): 91-114.

Donatello, Luis Miguel. "Conflictividad política y conflictividad religiosa en la Argentina moderna: procesos de ‘teologización' de la política”. Sí, somos americanos. Revista de estudios transfronterizos 8.1 (2006): 83-104.

Donatello, Luis Miguel. "Catolicismo y elites en la Argentina del siglo XXI: individualización y heterogeneidad”. Estudios sociológicos 29.87 (2011): 833-855. 
Trayectorias sociales y legitimidades político-religiosas en el Senado argentino a comienzos...

Esquivel, Juan Cruz. "Religious and Politics in Argentina. Religious influence on parliamentary decisions on sexual and reproductive rights". Latin American Perspectives 43 (2016): 133-143.

Giménez Béliveau, Verónica e Irrazábal, Gabriela. "Católicos en Argentina: hacia una interpretación de su diversidad”. Sociedad y religión, 20.32-33 (2010): 42-59.

Hervieu-Léger, Danièle. "Catolicismo: el desafío de la memoria". Sociedad y Religión.14/15 (1994): 9-28.

Irrazábal, Gabriela. "Religión y salud: la intervención pública de agentes religiosos católicos formados en bioética en el debate parlamentario sobre la muerte digna en la Argentina". Salud Colectiva 11.3 (2015): 331-349.

Levita, Gabriel. "Política y religión en el Senado argentino: el debate sobre el matrimonio para personas del mismo sexo en 2010". Revista Latinoamericana de Investigación Crítica, CLACSO 3.5 (2016): 39-58.

Levita, Gabriel. “¿De patricios a plebeyos? Sociología de las elites políticas. El Senado y los senadores argentinos en la primera década del siglo XXI". Estudios Políticos 51 Universidad de Antioquia (2017): 13-35.

Levita, Gabriel. “¿Qué pretende usted de mí?’ Enfrentando obstáculos en las entrevistas a elites en una investigación sobre los senadores nacionales argentinos. Revista Latinoamericana de Metodología de las Ciencias Sociales 8.1 Universidad Nacional de La Plata (en prensa).

Mallimaci, Fortunato. "Catolicismo y militarismo en la Argentina (1930-1983). De la Argentina liberal a la Argentina católica". Revista de Ciencias Sociales.4 (1996): 181-218.

Mora y Araujo, Manuel. “El ciclo político argentino". Desarrollo Económico, 22.86 (1982): 203-230.

Oro, Ari Pedro. "Consideraçoes sobre a modernidade religiosa". Sociedad y Religión.14/15 (1996): 61-70.

Sgró Ruata, María Candelaria y Vaggione, Juan Marco. "Las marcas de lo religioso en la política sexual: debate legislativo y matrimonio entre personas del mismo sexo en Argentina". Soc. e Cult. (Goiânia), 15.2 (2012): 331-345.

Vaggione, Juan Marco y Jones, Daniel. "La política sexual y las creencias religiosas: el debate por el matrimonio para las parejas del mismo sexo (Argentina, 2010)". Revista de Estudios Sociales.51 (2014): 105-117. 
Vaggione, Juan Marco. "Sexual Rights and Religion: Same-sex Marriage And Lawmakers' Catholic Identity In Argentina". University of Miami Law Review. 65.3 (2011): 935-954.

\section{Tesis, ponencias, documentos y otros Inéditos}

Arnoux, Elvira. "La reformulación interdiscursiva en "Análisis del discurso"”. Ponencia presentada en el $V$ Congreso Nacional de Investigaciones Lingüísticas y Filológicas. Lima: Universidad Ricardo Palma, 2004. 